\title{
FORMULASI DAN OPTIMASI BASIS GEL CARBOPOL 940 DENGAN BERBAGAI VARIASI KONSENTRASI
}

\author{
Utami Wahyu Hidayanti", Jaka Fadraersada, Arsyik Ibrahim \\ Laboratorium Penelitian dan Pengembangan Kefarmasian "Farmaka Tropis", \\ Fakultas Farmasi, Universitas Mulawarman, Samarinda \\ *Email : uwhidayanti@gmail.com
}

\begin{abstract}
The purpose of this study is to find a stable formula of gel bases. Gel bases were made in four formulas by using Carbopol 940 0,5\%, 1\%, 1,5\%, and 2\%. Optimization of gel bases includes organoleptic, homogeneity, pH test, viscosity test and the dispersive power during 16 days. This research is an experimental laboratory. Results obtained in the organoleptic seen from the color transparent, semi-solid dosage forms and distinctive smell of Carbopol 940, homogeneity test did not experience any clumping, $\mathrm{pH}$ test showed $\mathrm{pH}$ range from 6,72-7,82, viscosity test showed range from 18,98-36,38 Pa.S and dispersive power test showed range from 4,33 cm-6,87 cm. The result showed that gel base formula by using Carbopol 940 0,5\% was accordance with the standards.
\end{abstract}

Keywords: Carbopol 940, Gel Bases, Optimization

\begin{abstract}
ABSTRAK
Tujuan dari penelitian ini adalah untuk mendapatkan formula basis gel yang stabil. Basis gel dibuat dalam empat formula dengan menggunakan Carbopol 940 0,5\%, $1 \%, 1,5 \%$, dan $2 \%$. Optimasi basis gel meliputi organoleptik, homogenitas, uji $\mathrm{pH}$, uji viskositas dan daya sebar selama 16 hari. Penelitian ini merupakan eksperimental laboratorium. Hasil yang diperoleh pada pengujian organoleptik yaitu dilihat dari warna yang transparan, bentuk sediaan semi padat dan bau khas Carbopol 940, uji homogenitas menunjukkan bahwa basis gel tidak mengalami penggumpalan apapun, uji $\mathrm{pH}$ menunjukkan kisaran $\mathrm{pH}$ dari 6,72-7,82, uji viskositas menunjukkan kisaran viskositas 18,98-36,38 Pa.S dan uji daya sebar menunjukkan kisaran diameter dari 4,33 cm-6,87 cm. Hasil penelitian menunjukkan bahwa formula basis gel dengan menggunakan Carbopol 940 0,5\% telah sesuai dengan standar.
\end{abstract}

Kata Kunci: Carbopol 940, Basis Gel, Optimasi 


\section{PENDAHULUAN}

Gel, kadang-kadang disebut jeli, merupakan sistem semipadat terdapat dari suspensi yang dibuat dari partikel anorganik yang kecil atau molekul organik yang besar, terpenetrasi oleh suatu cairan. Jika massa gel terdiri dari jaringan partikel kecil terpisah, gel digolongkan sebagai sistem dua fase (misalnya gel aluminium hidroksida). Dalam sistem dua fase, jika ukuran partikel dari fase terdisper relatif besar, massa gel kadang-kadang dinyatakan sebagai magma (misalnya magma bentonit) [1]. Komposisi sediaan gel umumnya terdiri dari komponen bahan yang dapat mengembang dengan adanya air, humektan, dan pengawet, adakalanya diperlukan pula bahan yang dapat meningkatkan penetrasi bahan berkhasiat [2].

Menurut Bakker [3], menyatakan bahwa gel merupakan sistem yang heterogen. Pada sediaan gel, fase padat berada dalam struktur tiga dimensi sehingga partikel pada fase padat tidak dapat berpindah melewati fase cair. Agar fase padat tetap stabil berada dalam stuktur tiga dimensi maka partikel fase padat harus membentuk ikatan sekunder dengan partikel lainnya (ikatan van der Waals). Stabilitas dari sediaan gel bergantung pada :

a. Bentuk dari partikel dari fase padat.

b. Karakteristik fisiko-kimia dari fase padat dan kemampuannya untuk membentuk ikatan sekunder.

c. Konsentrasi dari fase padat.

d. Karakteristik fisiko-kimia dari fase cair.

Berdasarkan uraian tersebut, maka akan dilaksanakan penelitian dengan tujuan memperoleh formulasi basis gel yang stabil secara fisiko-kimia yang nantinya akan digunakan dalam pembuatan sediaan gel untuk penggunaan antiseptik tangan. Bahan yang digunakan sebagai basis gel adalah Carbopol 940. Teknik evaluasi yang dilakukan antara lain, pengujian organoleptik, homogenitas, uji $\mathrm{pH}$, pengukuran viskositas, dan daya sebar. Bentuk sediaan gel sangat disukai oleh masyarakat umum sebagai antiseptik tangan atau lebih dikenal dengan hand sanitizer.

\section{METODE PENELITIAN}

\section{Bahan}

Bahan yang digunakan dalam penelitian ini antara lain: Carbopol 940, propilenglikol, metil paraben, TEA, dan aquades.

\section{Peralatan}

Alat yang digunakan dalam penelitian ini antara lain: labu ukur, timbangan analitik, gelas kimia, magnetic stirer, hot plate, pot salep, $\mathrm{pH}$ meter, viskometer, keping kaca, anak timbang $150 \mathrm{~g}$. 


\section{Prosedur}

\section{Formulasi basis sediaan gel}

Basis gel yang terdiri dari carbopol, TEA, propilenglikol, metil paraben, dan aquades dibuat menjadi 4 formula berbeda yaitu dengan membuat variasi konsentrasi dari carbopol. Methylparaben $(0,2 \%)$ dilarutkan dalam aquades dengan memanaskan hingga suhu $70^{\circ} \mathrm{C}$, selanjutnya ditambahkan pembentuk gel (Carbopol) diaduk hingga mengembang dan membentuk gel, kemudian ditambahkan bahan lain seperti PG (15\%) sebagai humektan dan TEA sebagai platisizer dan penetral $\mathrm{pH}$ Carbopol. Carbopol dibuat dengan variasi konsentrasi $0,5 \%, 1 \%, 1,5 \%$ dan $2 \%$. Basis sediaan gel dibuat tanpa bahan aktif.

Tabel 1. Formula Basis dengan Variasi Konsentrasi

\begin{tabular}{ccccc}
\hline \multirow{2}{*}{ Bahan } & \multicolumn{4}{c}{ Formula Basis $(\% \mathrm{~b} / \mathrm{b})$} \\
\cline { 2 - 5 } & $\mathrm{B}_{1}$ & $\mathrm{~B}_{2}$ & $\mathrm{~B}_{3}$ & $\mathrm{~B}_{4}$ \\
\hline Carbopol & 0,5 & 1 & 1,5 & 2 \\
TEA & 1 & 1,5 & 2 & 2,5 \\
PG & 15 & 15 & 15 & 15 \\
Methylparaben & 0,2 & 0,2 & 0,2 & 0,2 \\
Aquades & ad 100 & ad 100 & ad 100 & ad 100 \\
\hline
\end{tabular}

Keterangan: $B 1=$ Formula basis ke-1 dengan konsentrasi Carbopol 0,5\% dan TEA 1\%, B2= Formula basis ke-2 dengan konsentrasi Carbopol 1\% dan TEA 1,5\%, B3= Formula basis ke-3 dengan konsentrasi Carbopol 1,5\% dan TEA 2\%, dan B4= Formula basis ke-4 dengan konsentrasi Carbopol 2\% dan TEA 2,5\%.

\section{Optimasi basis sediaan gel}

Optimasi basis gel dilakukan untuk memperoleh basis gel yang dapat menghasilkan sediaan gel antiseptik yang stabil secara kimia-fisika. Masingmasing basis gel, diuji secara kimia-fisika yaitu pengujian organoleptik, pengujian homogenitas, pengujian $\mathrm{pH}$, pengujian viskositas, dan pengujian daya sebar.

Pengujian organoleptik dilakukan dengan cara pengamatan secara langsung yaitu warna dan bau dari gel yang dibuat. Gel biasanya jernih dengan konsistensi setengah padat [4]. Dilakukan pengamatan terhadap warna dan bau sediaan, apakah terjadi perubahan atau tidak.

Pengujian homogenitas dilakukan dengan cara mengoleskan sampel gel pada sekeping kaca atau bahan transparan lain yang cocok, sediaan harus menunjukkan susunan yang homogen dan tidak terlihat adanya butiran kasar [1].

Pengujian $\mathrm{pH}$ sediaan dilakukan dengan cara menggunakan alat $\mathrm{pH}$ meter digital. Alat $\mathrm{pH}$ meter dicelupkan pada sediaan gel yang telah diencerkan dengan aquades. Setelah tercelup dengan sempurna, dinyalakan alat $\mathrm{pH}$ meter dan selanjutnya ditunggu hingga angka pada layar $\mathrm{pH}$ meter menunjukkan angka yang stabil. $\mathrm{pH}$ sediaan gel harus sesuai dengan $\mathrm{pH}$ kulit yaitu 4,5 - 6,5. 
Viskositas diukur menggunakan alat viskometer Rheosys Merlin. Sediaan gel diletakkan dalam wadah yang berupa besi datar kemudian spindel yang telah dipasang pada tempatnya, didekatkan dengan sediaan dengan jarak $1 \mathrm{~mm}$, alat dinyalakan dan dibiarkan spindel berputar sesuai dengan waktu yang telah ditetapkan.

Pengujian daya sebar dilakukan dengan cara sampel gel sebanyak $1 \mathrm{~g}$ diletakkan di pusat antara dua kaca datar, dimana kaca sebelah atas dibebani dengan meletakkan anak timbangan sehingga mencapai bobot $150 \mathrm{~g}$. Pengukuran dilakukan sebanyak tiga kali.

\section{HASIL DAN PEMBAHASAN}

Optimasi basis dilakukan dengan cara uji organoleptik, uji homogenitas, uji $\mathrm{pH}$, uji viskositas, dan uji daya sebar. Pengujian dilakukan setiap 4 hari sekali selama 16 hari. Pengujian organoleptik dilakukan dengan cara mengamati bentuk, warna, dan bau.

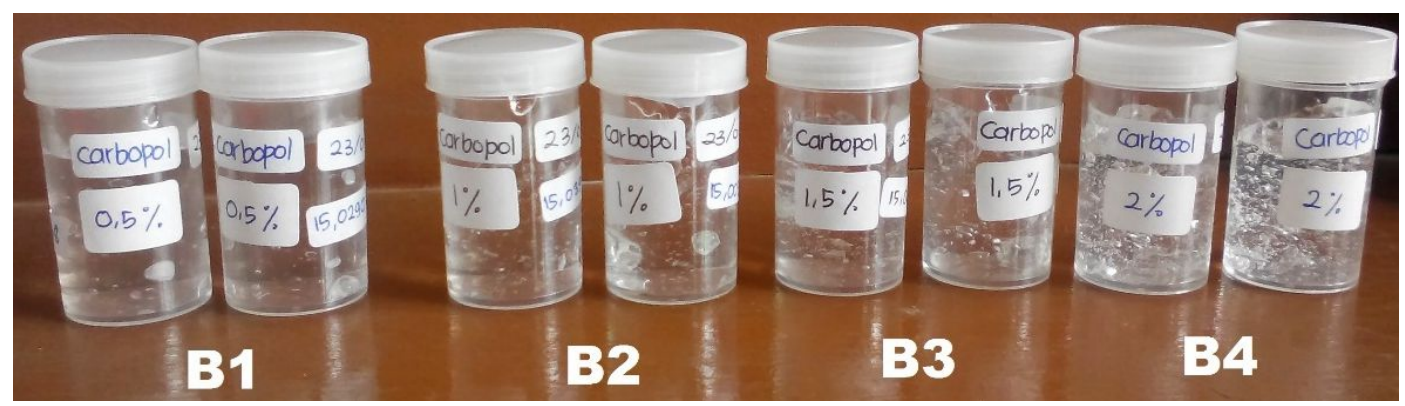

Gambar 1. Hasil Formulasi Basis Sediaan Gel. B1 = basis dengan konsentrasi Carbopol 0,5\% dan TEA 1\%, B2 = basis dengan konsentrasi Carbopol $1 \%$ dan TEA 1,5\%, B3 = basis dengan konsentrasi Carbopol 1,5\% dan TEA $2 \%$, dan B4 = basis dengan konsentrasi Carbopol 2\% dan TEA $2,5 \%$.

Diperoleh bentuk semi padat untuk semua basis gel dengan berbagai konsentrasi. Hasil menunjukkan bahwa semakin tinggi konsentrasi Carbopol maka konsistensi basis semakin kental. Semua sediaan berwarna bening dan berbau khas Carbopol.

Pengujian homogenitas dilakukan dengan menggunakan dua keping object glass. Sediaan yang homogen adalah sediaan yang di dalamnya tidak terdapat butiran-butiran dari bahan yang digunakan. Hasil pengujian menunjukkan bahwa sediaan homogen namun terdapat gelembung-gelembung yang dihasilkan pada saat proses pembuatan dengan menggunakan stirer. Semakin tinggi konsentrasi Carbopol maka semakin banyak gelembung. Basis gel dengan konsentrasi Carbopol $0,5 \%$ menunjukkan tidak adanya gelembung. 


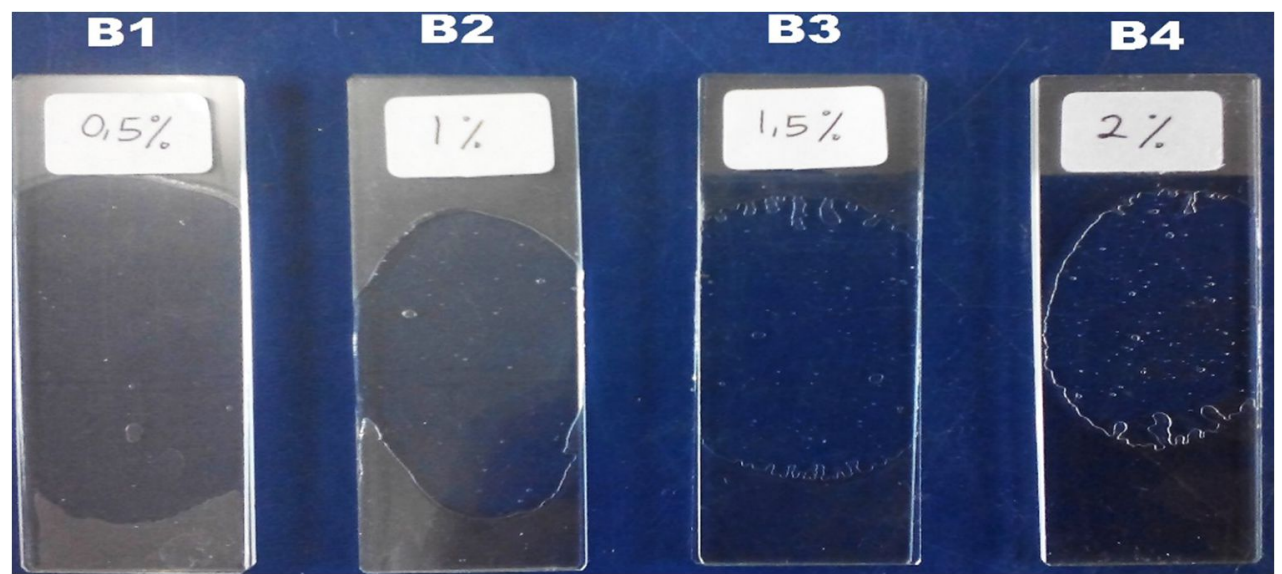

Gambar 2. Hasil Pengujian Homogenitas Basis Sediaan Gel Hari Ke-0

Pengujian $\mathrm{pH}$ menunjukkan bahwa pada konsetrasi Carbopol 0,5\%, $\mathrm{pH}$ cenderung stabil hingga hari ke-16 yaitu 7,01. Sediaan gel yang ideal untuk sediaan topikal menurut British Pharmacopeia [5], yaitu antara $\mathrm{pH}$ 6-8. Semakin tinggi konsentrasi Carbopol maka semakin tinggi $\mathrm{pH}$. Dari data tersebut maka basis gel dengan konsentrasi Carbopol 0,5\% menunjukkan $\mathrm{pH}$ yang sesuai dengan standar.

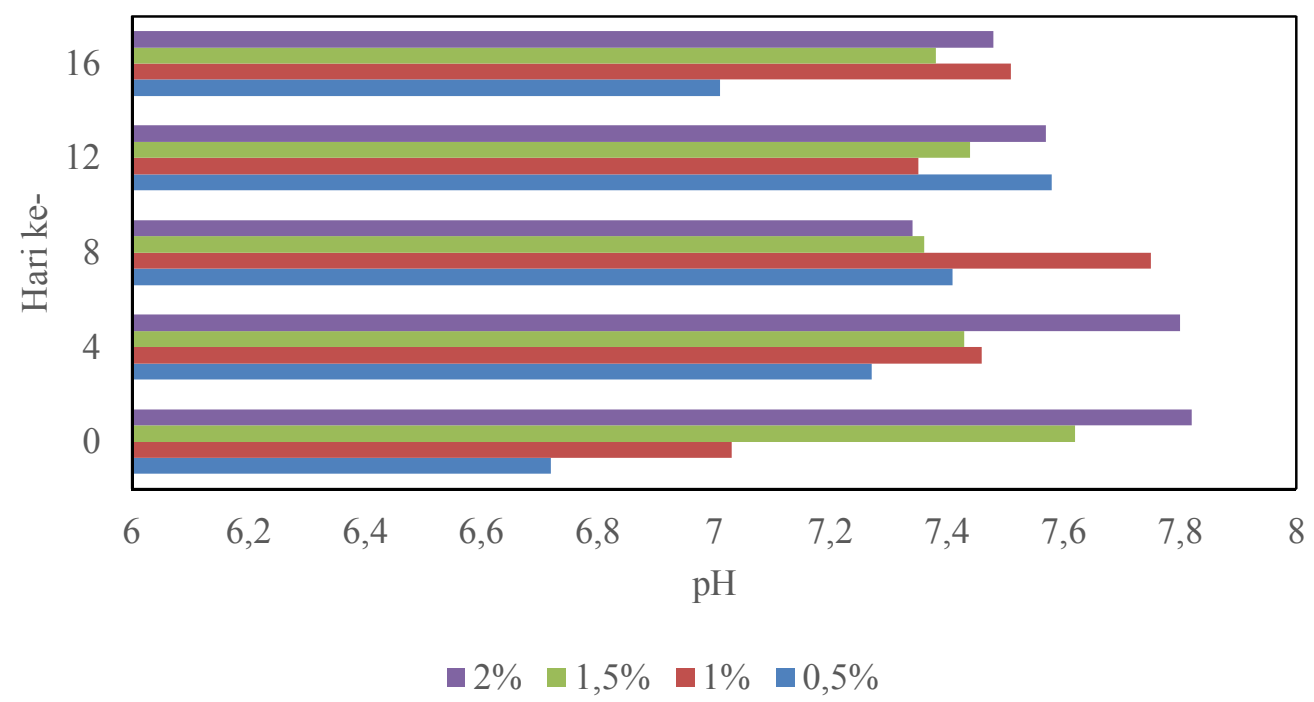

Gambar 3. Grafik Perbandingan pH Basis Sediaan Gel

Viskositas basis gel diukur dengan kecepatan 0,1 rpm selama 30 detik. Menurut SNI 16-4399-1996, nilai standar viskositas untuk sediaan gel adalah 6000$50000 \mathrm{cP}$ atau 6-50 Pa.S. Hasil pengukuran viskositas untuk seluruh formula, menghasilkan nilai yang termasuk dalam standar. Dapat dilihat dari grafik, bahwa nilai viskositas mengalami fluktuasi selama penyimpanan. 


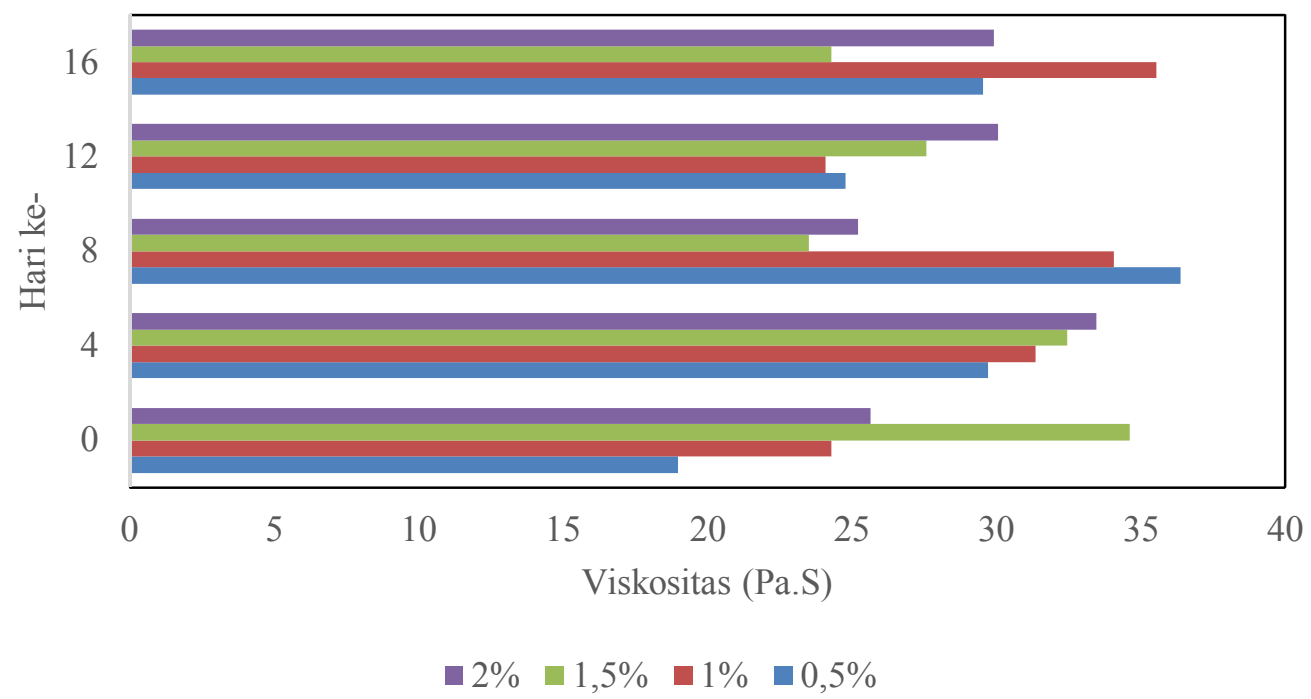

Gambar 4. Grafik Perbandingan Viskositas Basis Sediaan Gel
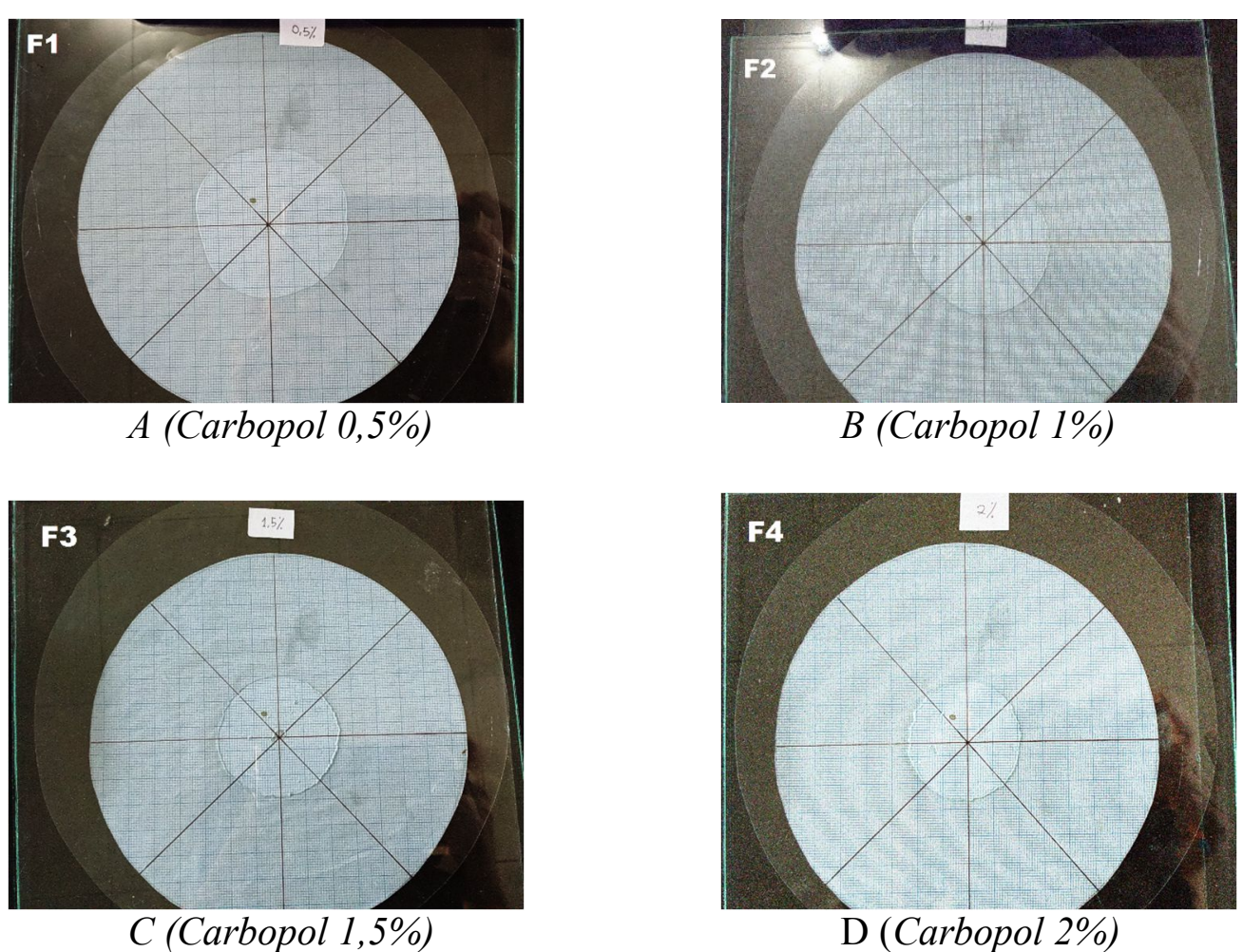

Gambar 5. Hasil Pengukuran Daya Sebar Basis Sediaan Gel Hari Ke-0 


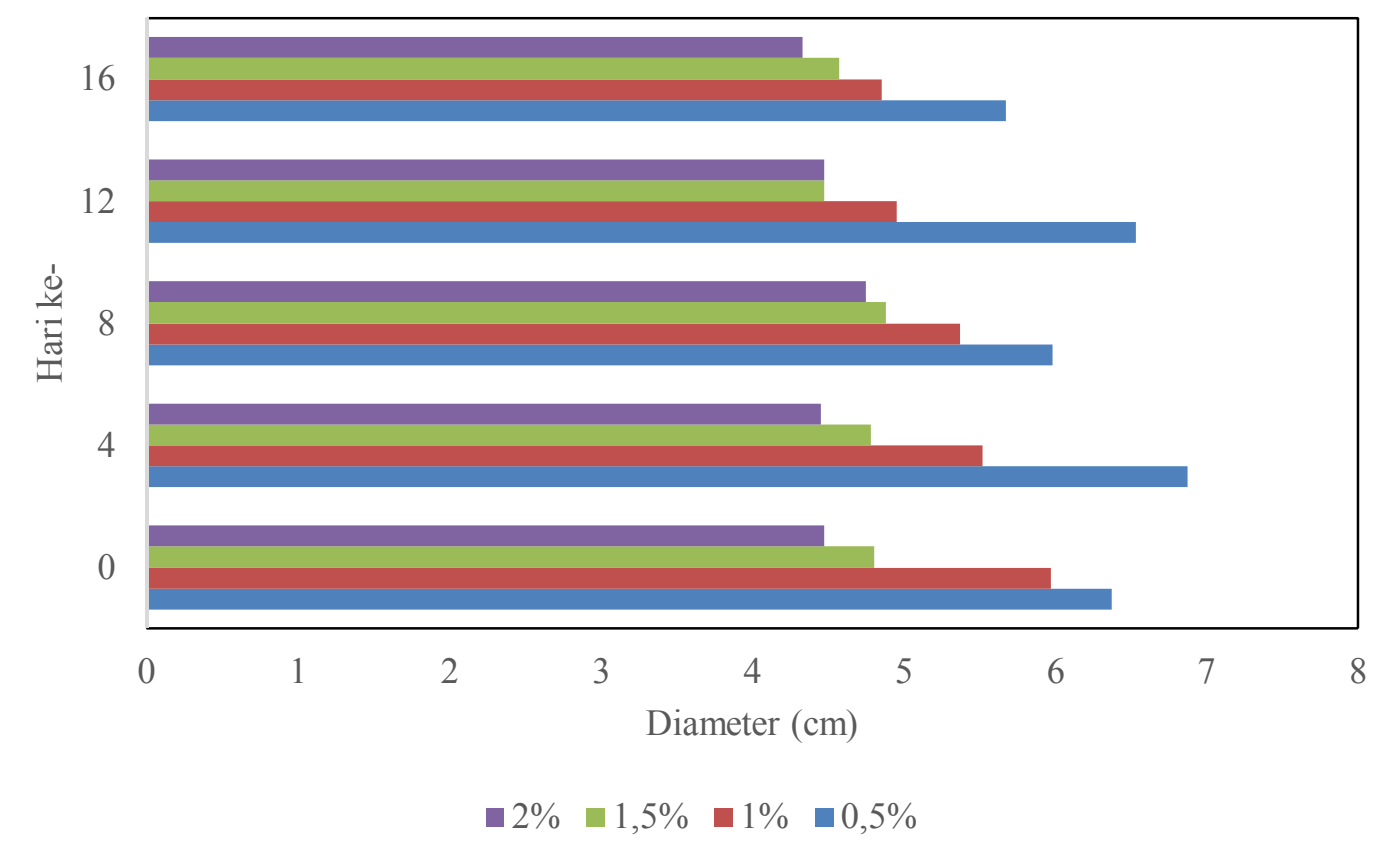

Gambar 6. Grafik Perbandingan Daya Sebar Basis Sediaan Gel

Pengujian daya sebar dilakukan dengan dua buah kaca dan anak timbang seberat 150 gram. Hasil menunjukkan bahwa semua basis mengalami penurunan daya sebar. Namun pada basis gel konsentrasi Carbopol 0,5\% menunjukkan daya sebar sebesar 6,37 cm pada hari ke-0 dan 5,67 cm pada hari ke-16. Daya sebar 5-7 $\mathrm{cm}$ menunjukkan konsistensi semisolid yang sangat nyaman dalam penggunaan [6].

\section{KESIMPULAN}

Berdasarkan hasil optimasi basis gel secara organoleptik, homogenitas, uji $\mathrm{pH}$, uji viskositas, dan daya sebar, maka basis gel yang akan digunakan dalam pembuatan sediaan gel untuk penggunaan antiseptik tangan adalah basis gel Carbopol 0,5\%.

\section{DAFTAR PUSTAKA}

[1] Departemen Kesehatan RI. 1995. Farmakope Indonesia Edisi 4. Departemen Kesehatan RI. Jakarta.

[2] Anwar, E. 2012. Eksipien Dalam Sediaan Farmasi. Dian Rakyat. Jakarta.

[3] Bakker, P., Herman W., Vincent G., Ben N., Rachel van der K., Nicolien W. 2012. Dermatological Preparations for The Tropics. Beta Science Shop. Netherlands.

[4] Ansel, H. C. 1989. Pengantar Bentuk Sediaan Farmasi Edisi Keempat. UI-Press. Jakarta. 
[5] British Pharmacopeia. 2007. Volume III. The Stationery Office. London.

[6] Garg, A., Aggarwal, D., Garg, S., and Sigla, A. K. 2002. Spreading of Semisolid Formulation: An Update. Pharmaceutical Technology. 